\title{
Comparison between 5-day aprepitant and single-dose fosaprepitant meglumine for preventing nausea and vomiting induced by cisplatin-based chemotherapy
}

\author{
Yosuke Ando $^{1}$ • Takahiro Hayashi ${ }^{1}$ - Kaori Ito ${ }^{2,3} \cdot$ Eri Suzuki $^{2} \cdot$ Naoyuki Mine $^{2}$. \\ Ayumi Miyamoto ${ }^{2}$ Miyuki Oya ${ }^{1}$ - Hidezo Matsuda ${ }^{1}$ - Ami Isaji ${ }^{1}$. Toru Nakanishi ${ }^{4}$. \\ Kazuyoshi Imaizumi $^{4}$. Tomoyuki Shibata ${ }^{5}$ Tatsuyoshi Okada ${ }^{6} \cdot$ Kazuo Sakurai $^{6}$. \\ Kensei Naito $^{6}$ • Ichiro Uyama $^{7} \cdot$ Kenji Kawada $^{8} \cdot$ Hiroshi Takahashi $^{9} \cdot$ Shigeki Yamada $^{1}$
}

Received: 30 April 2015 / Accepted: 13 July 2015 / Published online: 25 July 2015

(C) The Author(s) 2015. This article is published with open access at Springerlink.com

\begin{abstract}
Purpose We aimed to compare the preventive effect of 5-day administration of aprepitant with single administration of fosaprepitant meglumine against nausea and vomiting symptoms due to highly emetogenic chemotherapy regimens comprising cisplatin (CDDP).

Methods Subjects were inpatients who underwent chemotherapy for gastric cancer, esophageal cancer, lung cancer, or head and neck cancer with a regimen comprising $60 \mathrm{mg} / \mathrm{m}^{2}$ or higher dose of CDDP. In this randomised, open-label, controlled study, the subjects were assigned to a group given aprepitant for 5 days or a group given a single administration of fosaprepitant meglumine. The nausea and vomiting symptoms that emerged within 7 days after the first CDDP administration were investigated with a questionnaire form; the results were compared between the two groups. Risk factors affecting nausea and vomiting symptoms were also investigated.

Results Of the 101 patients enrolled, 93 patients were included (48 in the 5-day aprepitant group and 45 in
\end{abstract}

Takahiro Hayashi

taka-h@fujita-hu.ac.jp

1 Department of Clinical Pharmacy, School of Medicine, Fujita Health University, 1-98, Dengakugakubo, Kutsukake, Toyoake, Aichi 470-1192, Japan

2 Department of Pharmacy, Fujita Health University Hospital, 1-98, Dengakugakubo, Kutsukake, Toyoake, Aichi 470-1192, Japan

3 Department of Hematology, Fujita Health University, 1-98, Dengakugakubo, Kutsukake, Toyoake, Aichi 470-1192, Japan

4 Department of Respiratory Medicine, Fujita Health University, 1-98, Dengakugakubo, Kutsukake, Toyoake, Aichi 470-1192, Japan the single fosaprepitant meglumine group). No significant intergroup differences in the complete response rate or the complete control rate were found over the entire period. The nausea score tended to increase from day 3 in both groups, but no significant intergroup difference was observed. Furthermore, the investigation of risk factors affecting moderate or severe nausea symptoms indicated that the fosaprepitant meglumine administration was not a risk factor.

Conclusions Single administration of fosaprepitant meglumine was not inferior to 5-day administration of aprepitant for preventing acute and delayed nausea and vomiting symptoms occurring after administration of CDDP $\left(60 \mathrm{mg} / \mathrm{m}^{2}\right.$ or higher $)$.

Keywords Aprepitant · Fosaprepitant meglumine · Chemotherapy-induced nausea and vomiting $\cdot$ Complete response $\cdot$ Highly emetogenic chemotherapy

Department of Gastroenterology, Fujita Health University, 1-98, Dengakugakubo, Kutsukake, Toyoake, Aichi 470-1192, Japan

6 Department of Otolaryngology, Fujita Health University, 1-98, Dengakugakubo, Kutsukake, Toyoake, Aichi 470-1192, Japan

7 Department of Upper Gastrointestinal Surgery, Fujita Health University, 1-98, Dengakugakubo, Kutsukake, Toyoake, Aichi 470-1192, Japan

8 Department of Medical Oncology, Fujita Health University, 1-98, Dengakugakubo, Kutsukake, Toyoake, Aichi 470-1192, Japan

9 Division of Medical Statistics, Fujita Health University, 1-98, Dengakugakubo, Kutsukake, Toyoake, Aichi 470-1192, Japan 


\section{Introduction}

Chemotherapy-induced nausea and vomiting (CINV) necessitates modifications to the regimen in severe cases and is reportedly a factor affecting the prognosis of cancer treatment $[1,2]$. CINV reduced the amount of food intake, resulting in malnutrition, body weight loss and reduced performance status (PS) [3]. The reduced PS leads to an increased incidence of haematotoxicity [4]. Therefore, it is critical to prevent CINV. The emetogenicity of anti-cancer agents has been categorised according to their risk levels in guidelines by the Multinational Association of Supportive Care in Cancer (MASCC) [5], the American Society of Clinical Oncology (ASCO) [6] and the National Comprehensive Cancer Network (NCCN) [7]. In all of these guidelines, cisplatin (CDDP) is classified as a highly emetogenic agent $[8,9]$. Appropriate measures against CINV are essential in CDDP administration. In addition, CDDP is characterised by a biphasic emergence of CINV in the acute (within $24 \mathrm{~h}$ after starting the administration) and late phases (beyond $24 \mathrm{~h}$ after starting the administration) [10].

The development of antiemetic drugs has been remarkable; selective $5-\mathrm{HT}_{3}$ receptor antagonists were developed in the 1990s. Ohmatsu et al. have reported that the granisetron+ dexamethasone group fared better than the metoclopramide+ dexamethasone group with respect to the prevention of CINV during CDDP administration [11]. Thereafter, it has been shown that the NK-1 receptor is closely involved in CINV [12], and substance $P$ induces vomiting through binding to the NK-1 receptor in the central nervous system [13-15]. The NK-1 receptor has also been noted as a new target for antiemetic therapy [16]. NK-1 receptor antagonist, aprepitant, has been developed and was listed in the NCCN guidelines in 2004. Aprepitant is an anti-emetic agent with a novel mechanism of action. It inhibits the binding of substance P to the NK-1 receptor in the central nervous system $[17,18]$ and reduces the incidence of acute and delayed nausea and vomiting symptoms significantly when used in combination with the conventional anti-emetic therapy (concomitant use of ondansetron and dexamethasone) [19]. Aprepitant has also been listed in the drug price standard in Japan since December 2009 and accordingly included as an effective anti-emetic that is also used for delayed emesis in 'Guidelines for Proper Use of Anti-emetics Version 1', which was created by the Japan Society of Clinical Oncology in May 2010. Subsequently, fosaprepitant meglumine, a phosphorylated prodrug of aprepitant with improved water solubility, was developed.

The non-inferiority of fosaprepitant meglumine to aprepitant in the anti-emetic effect in the acute and late phases has been demonstrated in a phase III study conducted in 27 countries to compare aprepitant administered for 3 days and fosaprepitant meglumine administered once in patients receiving the highly emetogenic anti-cancer agent CDDP ( $\geq 70 \mathrm{mg}$ / $\mathrm{m}^{2}$ ) [20]. Based on this result, fosaprepitant meglumine has been listed in the NCCN guidelines since 2011 and also included in the Japanese drug price standard in November 2011. Thereafter, a phase III clinical study in Japanese patients treated with CDDP $\left(\geq 70 \mathrm{mg} / \mathrm{m}^{2}\right)$ [21] was conducted and demonstrated a superior effect in the fosaprepitant meglumine group compared to that of the placebo group. However, no studies have been conducted to directly compare the anti-emetic effect of aprepitant with fosaprepitant meglumine in Japanese patients. Moreover, although guidelines released by the Japan Society of Clinical Oncology have recommended 3 days of aprepitant administration, a domestic phase II clinical trial targeting Japanese subjects [22] has verified a 5-day administration of aprepitant. This is because aprepitant was developed in Japan as a drug that should be administered for 5 days. However, the overseas clinical trials [19, 23, 24] tested the 3-day regimen of aprepitant, and the NCCN guidelines [7] recommended the 3-day technique. Therefore, after carefully considering the domestic phase II clinical trial results, the Ministry of Health, Labour and Welfare in Japan decided that sufficient efficacy could be anticipated with 3-day aprepitant administration for Japanese patients and that up to 5 days of administration would be acceptable. In light of the above facts, we decided that it was necessary to compare the 5-day administration of aprepitant and a single administration of fosaprepitant meglumine to compare the efficacy of aprepitant and fosaprepitant meglumine in Japanese patients who had received CDDP, a highly-emetic anticancer agent. Moreover, a phase III trial [20] that compared the 3-day administration of aprepitant and the single administration of fosaprepitant meglumine compared antiemetic effects until 5 days after CDDP administration; however, this study did not examine the subsequent progress of the patients. Therefore, we evaluated the degree of nausea and vomiting symptoms until day 7 in Japanese patients who underwent chemotherapy with CDDP at Fujita Health University Hospital (the day of CDDP administration was day 1) to prospectively compare the effects on nausea and vomiting symptoms in a 5-day aprepitant administration group and in a single-dose fosaprepitant meglumine administration group.

\section{Subjects and methods}

\section{Subjects}

In this study, we enrolled Japanese patients who started to receive chemotherapy comprising CDDP $\left(\geq 60 \mathrm{mg} / \mathrm{m}^{2}\right)$ for lung cancer, gastric cancer, esophageal cancer, or head and neck cancer between January 2013 and March 2014 at the Fujita Health University Hospital. They provided consent to participate in this study after the intent of the study was explained to them. However, any patient who had nausea or vomiting within $24 \mathrm{~h}$ before starting administration of anti- 
neoplastic drugs, who could not receive a drug orally, who could not answer the questionnaire, who did not provide consent or who was considered unsuitable to this study was excluded.

\section{Investigations}

An equal number of subjects were randomly assigned to the aprepitant treatment group (group A; aprepitant, a 5- $\mathrm{HT}_{3}$ receptor antagonist and dexamethasone) and the fosaprepitant meglumine treatment group (group B; fosaprepitant meglumine, a $5-\mathrm{HT}_{3}$ receptor antagonist and dexamethasone). Anti-emetic agents were used in both groups in accordance with the dosage instruction on the package inserts. Specifically, in group A, aprepitant was administered at $125 \mathrm{mg}$ on day 1 (the day administration of anti-neoplastic agents started) and at $80 \mathrm{mg}$ daily on days $2-5$, and a $5-\mathrm{HT}_{3}$ receptor antagonist (palonosetron [0.75 mg], granisetron [3 $\mathrm{mg}$ ] or azasetron [10 mg]) was administered, along with $6.6-9.9 \mathrm{mg}$ of dexamethasone on day 1 and 3.3-6.6 mg daily on days 2-4. Group B subjects received fosaprepitant meglumine at $150 \mathrm{mg}$ on day 1, 6.6-9.9 mg of dexamethasone on day 1 and 3.3$6.6 \mathrm{mg}$ daily on days $2-4$, and a $5-\mathrm{HT}_{3}$ receptor antagonist (palonosetron $[0.75 \mathrm{mg}$ ], granisetron $[3 \mathrm{mg}$ ] or azasetron [10 mg]).

\section{Assessment}

To survey the occurrence of nausea and vomiting, we prepared a nausea/vomiting recording form (Fig. 1) based on the MAT (questionnaire about nausea and vomiting), which was developed by the Multinational Association of Supportive Care in Cancer (MASCC). Investigators interviewed their patients daily about states of nausea and vomiting symptoms from day 1 (the day CDDP was administered) to day 7 and recorded the responses. Based on a report from Longo et al. [25], we conducted patient interviews only for the first course to minimise bias. Nausea symptoms were surveyed and recorded by a pharmacist according to the numeric rating scale (NRS; 11point scale, in which 0 represents a condition without nausea and 10 represents a condition with the worst conceivable nausea). The results were then categorised according to the Likert scale into 'no symptom or mild' (NRS, 0-2), 'moderate' (3-6) and 'severe' (7-10). For vomiting symptoms, the number of times vomiting (including dry vomiting) occurred was surveyed every day and evaluated according to the National Cancer Institute-Common Terminology Criteria for Adverse Events Version 4.0 (NCI-CTCAE ver. 4.0). With regard to the effects of the drugs on nausea and vomiting, the proportion of the patients who did not experience vomiting or dry vomiting (the complete response [CR] rate) and the proportion of the patients who did not experience vomiting or dry vomiting and had 'no symptom or mild' nausea (the complete control $[\mathrm{CC}]$ rate) were determined and compared between the two groups. We also investigated age, sex, cancer type, administration of concomitant radiotherapy and use of opioid as potential confounding factors. We also examined susceptibility to motion sickness, history of alcohol consumption and history of pregnancy, which were proposed as risk factors for nausea and vomiting by Koeller et al. [26].

\section{Statistical analysis}

Continuous variables in patient background data were expressed as mean $\pm \mathrm{SD}$, and intergroup comparison was performed with an unpaired $t$ test. Patient background data composed of a nominal scale was expressed in $\%$, and $\chi^{2}$ test was used for intergroup comparisons. $\chi^{2}$ test was used to compare the $\mathrm{CR}$ and $\mathrm{CC}$ rates between the two groups. The nausea score was expressed in a form of median (first quartile-third quartile), and changes in the score over time were compared with the Friedman test, followed by multiple comparisons with the Wilcoxon signed-rank test with Bonferroni correction. Intergroup comparisons were performed with the twoway repeated measures analysis of variance. To explore the risk factors for nausea and vomiting, univariate analysis was performed, and then multivariate logistic regression analysis was performed on items with a significance level less than $10 \%$. The analysis software used was SPSS Ver. 22.0 (IBM Corporation, Armonk, NY, USA); the significance level used was less than $5 \%$.

\section{Statement of ethics}

This study was conducted in compliance with the 'Ethical Guidelines for Clinical Research' with an approval from the Ethical Review Board for Epidemiology/Clinical Research of our hospital.

\section{Results}

\section{Patients}

Of 101 patients enrolled, 8 patients were excluded as per the exclusion criteria, and the remaining 93 patients were randomised: 48 in group A and 45 in group B. The patient inclusion flowchart is presented in Fig. 2. No differences were noted in the patient background between the two groups (Table 1).

\section{Efficacy}

The $\mathrm{CR}$ rates in the acute phase (days 1 and 2), the first stage of the late phase (days 3-5) and the second stage of the late phase (days 6 and 7) were separately compared between group 
Fig. 1 Nausea/vomiting recording form

\begin{tabular}{|c|c|c|c|c|c|c|c|}
\hline & $\begin{array}{l}\text { 1st day } \\
(/ /)\end{array}$ & $\begin{array}{l}\text { 2nd day } \\
(/ /)\end{array}$ & $\begin{array}{l}\text { 3rd day } \\
(/ /)\end{array}$ & $\begin{array}{l}\text { 4th day } \\
(/ /)\end{array}$ & $\begin{array}{l}\text { 5th day } \\
(/ /)\end{array}$ & $\begin{array}{l}\text { 6th day } \\
(/ /)\end{array}$ & $\begin{array}{l}7 \text { th day } \\
(/ /)\end{array}$ \\
\hline Nausea & & & & & & & \\
\hline Vomiting & & & & & & & \\
\hline
\end{tabular}

Please fill in the table with the appropriate number in refer ence to the explanation.

ONausea

Please choose the poor est degree of nausea over the course of 1 day.

\begin{tabular}{|c|c|c|c|}
\hline $\begin{array}{c}\text { no } \\
\text { symptoms }\end{array}$ & $\begin{array}{c}\text { can drink } \\
\text { and eat a little }\end{array}$ & $\begin{array}{c}\text { can drink } \\
\text { but cannot eat }\end{array}$ & $\begin{array}{c}\text { can neither } \\
\text { eat }\end{array}$ \\
\hline & 1 & 1 & $\downarrow$ \\
\hline 0 & 4 & 7 & 10 \\
\hline
\end{tabular}

\footnotetext{
Ovomiting

1. No vomiting occurred

2. 1-2 times

3. 3-5 times

4. More than 6 times
}

Please count the number of times that vomiting continued for more than 5 minutes over the course of 1 day

A and group B. The CR rates in group A and group B were, respectively, 97.9 and $97.8 \%$ for the acute phase $(P=0.96)$, 87.5 and $84.4 \%$ for the first stage of the late phase $(P=0.67)$ and 89.6 and $90.0 \%$ for the second stage of the late phase $(P=0.91)$, showing no significant differences between the two groups in all phases (Fig. 3a). The CR rate for the entire period was $85.4 \%(41 / 48)$ in group $\mathrm{A}$ and $82.2 \%(37 / 45)$ in group $\mathrm{B}$, also showing no significant difference $(P=0.90)$. While comparing the $\mathrm{CR}$ rate between the acute and late phases in group A, no significant differences were found between the acute phase and the first stage $(P=0.36)$ or the second stage of the late phase $(P=0.63)$. The $\mathrm{CR}$ rate was similarly compared between the phases also in group B, but no significant differences were found between the acute phase and the first stage $(P=0.19)$ or the second stage of the late phase $(P=0.60)$.

The CC rate was also separately compared between the two groups. The $\mathrm{CC}$ rates in group $\mathrm{A}$ and group $\mathrm{B}$ were, respectively, 77.1 and $91.1 \%$ for the acute phase $(P=0.066), 60.4$ and $73.3 \%$ for the first stage of the late phase $(P=0.19)$, and 66.7 and $71.1 \%$ for the second stage of the late phase $(P=$ $0.64)$. Although differences between the two groups were not of statistical significance in any phases, the $\mathrm{CC}$ rate in group $\mathrm{A}$

Fig. 2 Study flow chart

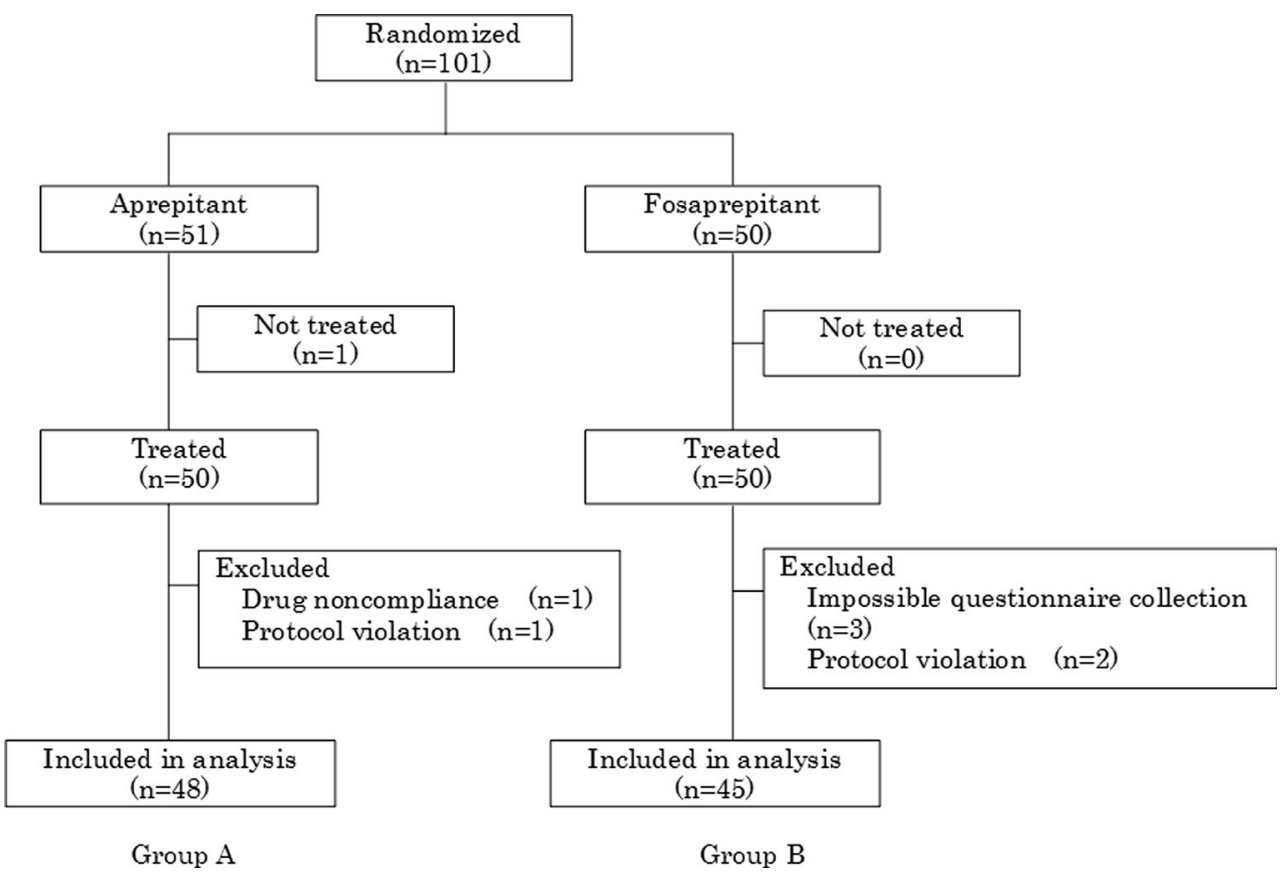


Table 1 Patient background

\begin{tabular}{llll}
\hline & Group A $(n=48)$ & Group B $(n=45)$ & $P$ value \\
\hline Age (years) & $61.7 \pm 11.7$ & $65.4 \pm 10.0$ & 0.099 \\
Male, Female & 40,8 & 34,11 & 0.35 \\
CDDP $\left(\mathrm{mg} / \mathrm{m}^{2}\right)$ & $70(60-80)$ & $70(60-80)$ & 0.61 \\
Cancer type & & & 0.85 \\
$\quad$ Lung cancer & 14 & 12 & \\
Gastric cancer & 15 & 10 & \\
Esophageal cancer & 7 & 9 & 0.90 \\
$\quad$ Head and neck cancer & 11 & 13 & 0.93 \\
$\quad$ Unknown primary & 1 & 1 & 0.80 \\
RT concomitantly used & 23 & 21 & 0.25 \\
Opioid concomitantly used & 3 & 3 & 0.51 \\
Alcohol consumption & 29 & 26 & 0.93 \\
Susceptible to motion sickness & 3 & 6 & \\
History of emesis due to pregnancy & 3 & 7 & \\
5-HT 3 receptor antagonist & & 22 & \\
$\quad$ Palonosetron & 23 & 25 &
\end{tabular}

$C D D P$ cisplatin, $R T$ radiotherapy

tended to be slightly lower in the acute phase (Fig. 3b). The $\mathrm{CC}$ rate for the entire period also did not differ significantly between group A $(60.4 \%, 29 / 48)$ and group B $(64.4 \%, 29 /$ 45) $(P=0.85)$. Comparisons of the $\mathrm{CC}$ rate between the acute and late phases in group A showed no significant differences between the acute phase and the first stage $(P=0.23)$ or the second stage of the late phase $(P=0.78)$. Similar phase-tophase comparisons of the $\mathrm{CC}$ rate in group $\mathrm{B}$ also showed no significant differences between the acute phase and the first stage $(P=0.16)$ or the second stage of the late phase $(P=0.093)$.

For day-to-day changes in the nausea score, while a significant consecutive increase was observed from day
3 to day 7 in group A, the score increased only on days 3 and 4 in group B. However, no significant differences were detected by the two-way repeated measures analysis of variance (Table 2).

\section{Risk factors}

Risk factors for moderate or severe nausea symptoms were investigated. The two factors 'age' and 'susceptible to motion sickness' were of near statistical significance in the univariate analysis, but the multivariate analysis indicated that neither was a risk factor (Table 3).
Fig. 3 Comparison of the $\mathrm{CR}$ and $\mathrm{CC}$ rates between group $\mathrm{A}$ and group B a

Complete responserate b

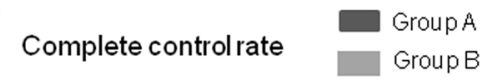

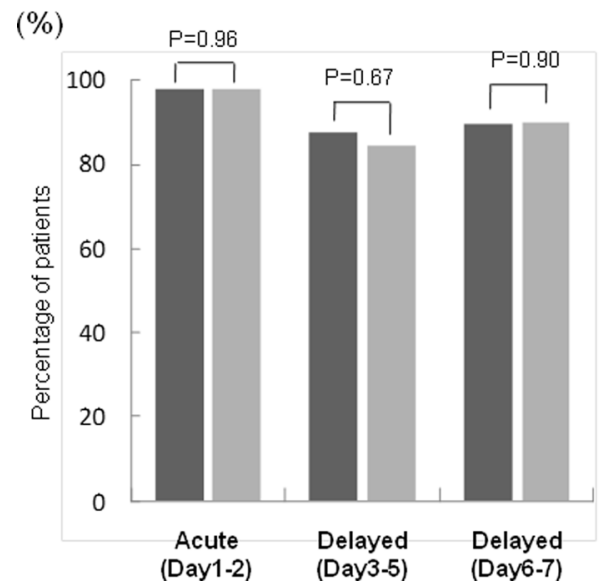

(\%)

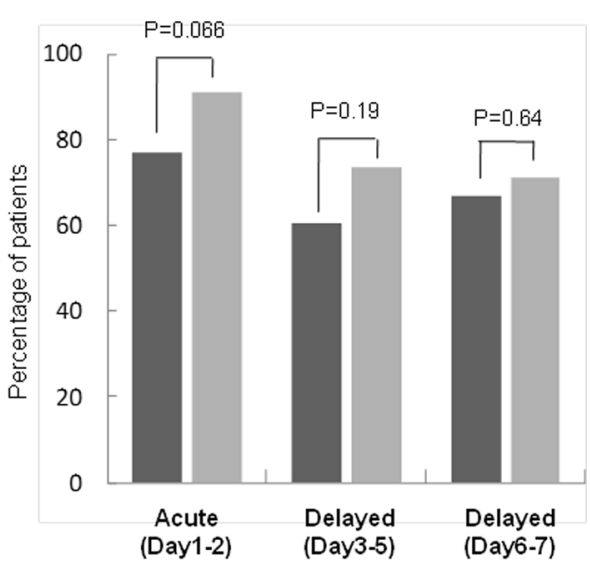


Table 2 Daily changes in nausea score in group A and group B

\begin{tabular}{lll}
\hline & Group A & Group B \\
\hline Day 1 & $0(0-0)$ & $0(0-0)$ \\
Day 2 & $0(0-1)$ & $0(0-0)$ \\
Day 3 & $0(0-3)^{*}$ & $0(0-1)^{*}$ \\
Day 4 & $1(0-3)^{* *}, * * *$ & $0(0-2)^{*}$ \\
Day 5 & $1(0-3)^{* *}, * * *$ & $0(0-2)$ \\
Day 6 & $0(0-3)^{* *}$ & $0(0-2)$ \\
Day 7 & $0(0-3)^{* *}$ & $0(0-2)$ \\
$P$ value (Friedman test) & 0.0013 & 0.0013 \\
\hline
\end{tabular}

$* P<0.05 ; * * P<0.01$ versus day $1 ; * * * P<0.05$ versus day 2 (Wilcoxon's signed-rank test followed by Bonferroni correction), $P=0.658$ (two-way repeated measures analysis of variance)

\section{Discussion}

For acute and delayed vomiting symptoms seen after CDDPbased chemotherapy, no difference in incidence was found between the 5-day aprepitant administration group and the single fosaprepitant meglumine administration group. Grunberg et al. compared the CR rate between the 3-day aprepitant administration group and the single fosaprepitant meglumine administration group of patients treated with at least $70 \mathrm{mg} / \mathrm{m}^{2}$ of CDDP and reported no significant intergroup differences in the acute phase ( 88.0 and $89.0 \%$, respectively) or the late phase (74.2 and $74.3 \%)$. Although this result was in agreement with that of our study, Grunberg et al. used a higher CDDP dose and administered aprepitant for 3 days rather than 5 days [20]. These differences in conditions may underlie a lower CR rate observed in their study than that in our study. While a phase II study in Japanese patients treated with CDDP $\left(\geq 70 \mathrm{mg} / \mathrm{m}^{2}\right)$ showed that the $\mathrm{CR}$ rate in the 5-day aprepitant administration group was higher than that of the placebo group [22], the CR rate for the entire study period in the 5-day aprepitant administration group was $70.5 \%$, which was lower than the rate obtained in our study. This difference may be attributable to the difference in the CDDP dose between the two studies. In this study, we intentionally chose a CDDP dose of $\geq 60 \mathrm{mg} / \mathrm{m}^{2}$ for the following reason; in the Japanese gastric cancer guidelines, the first-line drug therapy options include combination therapy with CDDP $\left(60 \mathrm{mg} / \mathrm{m}^{2}\right)$ and S-1 $\left(80 \mathrm{mg} / \mathrm{m}^{2}\right)$ [27], and we thought that patients with gastric cancer, for which CDDP is a first choice, should be included in CDDP studies about Japanese subjects. In the present study, the CDDP dose did not differ between the two groups, and it is highly unlikely that the results were affected by the difference in the CDDP dose.

Daily changes in the $\mathrm{CC}$ rate and nausea score were investigated, but neither showed significant differences between the two groups. Furthermore, the result from the logistic regression analysis of risk factors for nausea of moderate or higher severity indicated that fosaprepitant meglumine administration was not a risk factor. From these results, the nauseasuppressing effect of fosaprepitant meglumine administered
Table 3 Risk factors for moderate or severe nausea symptoms

\begin{tabular}{|c|c|c|c|c|}
\hline & \multicolumn{2}{|l|}{ Univariate analysis } & \multicolumn{2}{|l|}{ Multivariate analysis } \\
\hline & Odds ratio $(95 \% \mathrm{CI})$ & $P$ value & Odds ratio $(95 \% \mathrm{CI})$ & $P$ value \\
\hline Administration of fosaprepitant & $\begin{array}{l}0.84 \\
(0.36-1.95)\end{array}$ & 0.69 & & \\
\hline Age (years) & $\begin{array}{l}0.97 \\
(0.93-1.00)\end{array}$ & 0.075 & $\begin{array}{l}0.97 \\
(0.93-1.02)\end{array}$ & 0.21 \\
\hline Female & $\begin{array}{l}1.66 \\
(0.60-4.60)\end{array}$ & 0.33 & & \\
\hline $\mathrm{CDDP}\left(\mathrm{mg} / \mathrm{m}^{2}\right)$ & $\begin{array}{l}1.02 \\
(0.98-1.06)\end{array}$ & 0.24 & & \\
\hline Treatment with RT & $\begin{array}{l}1.08 \\
(0.47-2.51)\end{array}$ & 0.85 & & \\
\hline Concomitant use of opioid & $\begin{array}{l}1.72 \\
(0.33-9.03)\end{array}$ & 0.52 & & \\
\hline Alcohol consumption & $\begin{array}{l}0.67 \\
(0.29-1.58)\end{array}$ & 0.37 & & \\
\hline Susceptible to motion sickness & $\begin{array}{l}3.79 \\
(0.88-16.30)\end{array}$ & 0.073 & $\begin{array}{l}2.77 \\
(0.59-12.96)\end{array}$ & 0.20 \\
\hline Administration of palonosetron & $\begin{array}{l}1.01 \\
(0.44-2.34)\end{array}$ & 0.98 & & \\
\hline
\end{tabular}

$C D D P$ cisplatin, $R T$ radiotheraphy 
once was found non-inferior to that of aprepitant administered for 5 days. In studies on the effect of aprepitant or fosaprepitant meglumine in CDDP-treated patients, the CR and $\mathrm{CC}$ rates have been used often, but the results have been based on the rate determined for a certain period [18-21] rather than the rate changes followed over the course of the study. While a visual analog scale [19-20] and other scoring systems [21] are generally used to evaluate the nausea symptom, we used the interview survey of patients with NRS for detailed, daily evaluation of the symptom. The demonstration of the absence of intergroup differences, even when changes in the nausea symptom were investigated in detail with NRS, provides a more solid support for the prophylactic equivalence of the two agents. In the study conducted by Grunberg et al. to compare aprepitant and fosaprepitant meglumine, the anti-emetic effect was not investigated beyond 5 days after the CDDP administration. In contrast, our present study suggested that the anti-CINV effect of fosaprepitant meglumine persisted over 7 days after the single administration. This is a new and very intriguing finding.

Sekine et al. searched for risk factors that affected the incidence of CINV in multiple clinical studies conducted with chemotherapy-naïve patients in Japan and reported that the risk factors include female gender, less advanced age (less than 55 years) and no history of alcohol consumption. The risk of CINV emergence increases as the number of applicable risk factors increases [28]. However, our present investigation of risk factors for moderate or severe nausea indicated that no factors were influential. Moreover, the two groups were comparable in the number of risk factors: Patients with 1, 2 and 3 risk factors were, respectively, 20 (41.7\%), 7 (14.6\%) and 2 $(4.2 \%)$ in group A and $14(31.1 \%), 8(17.8 \%)$ and $2(4.4 \%)$ in group B. The risk factors reported by Sekine et al. were thus considered highly unlikely to have affected the results of the present study. In addition to aprepitant and fosaprepitant meglumine, the subjects in this study received another antiemetic selected from granisetron, azasetron and palonosetron. While granisetron and azasetron reportedly are as potent as ondansetron in terms of the anti-emetic effect [29-31], Hashimoto et al. [32] reported that the CR rate in patients treated with a highly emetic regimen comprising CDDP at a dose of $50 \mathrm{mg} / \mathrm{m}^{2}$ or higher tended to be lower in the granisetron group than in the palonosetron group (59.1 versus $65.7 \% ; P=0.0539)$. Based on this result, palonosetron administration was included as a variable in our risk factor analysis but was found uninfluential. This may be due to some differences in study conditions, but details remain unknown.

In Japanese patients treated with CDDP+5-FU (CDDP $80 \mathrm{mg} / \mathrm{m}^{2}$ on day $1+5-\mathrm{FU} 800 \mathrm{mg} / \mathrm{m}^{2}$ on days $\left.1-5\right)$ for head and neck cancer, Aoki et al. [33] investigated the nausea and vomiting symptoms over an observation period of 7 days from the start of chemotherapy (days 1-7) in the 3-day and the 5day aprepitant administration group. They reported that the effect was maintained for 7 days in the 5-day group, while the effect declined from day 6 onwards in the 3-day group. In the present study, we compared the $\mathrm{CR}$ and $\mathrm{CC}$ rates between the acute phase and the first and second stages of the late phase but did not find any apparent decline of the effect in the single fosaprepitant meglumine administration group or the 5-day aprepitant administration group. Although conditions were not identical, results from our present study corroborated the results obtained by Aoki et al., suggesting that single administration of fosaprepitant meglumine was non-inferior to the 5day administration of aprepitant in terms of persistence of the effect.

\section{Conclusions}

The single administration of fosaprepitant meglumine was as effective as the 5-day administration of aprepitant for preventing acute and delayed nausea and vomiting symptoms occurring after the administration of CDDP $\left(\geq 60 \mathrm{mg} / \mathrm{m}^{2}\right)$.

Acknowledgments We would like to thank the participating patients for their contribution to this study.

Conflict of interest The authors declare that they have no conflict of interest. We have full control of all primary data, and we agree to allow the journal to review the data if requested.

Funding No funding for this work was received.

Ethical approval All procedures performed in studies involving human participants were in accordance with the ethical standards of the institutional and/or national research committee and with the $1964 \mathrm{Hel}-$ sinki declaration and its later amendments or comparable ethical standards.

Informed consent Informed consent was obtained from all individual participants included in the study.

Open AccessThis article is distributed under the terms of the Creative Commons Attribution-NonCommercial 4.0 International License (http:// creativecommons.org/licenses/by-nc/4.0/), which permits any noncommercial use, distribution, and reproduction in any medium, provided you give appropriate credit to the original author(s) and the source, provide a link to the Creative Commons license, and indicate if changes were made.

\section{References}

1. Bonadonna G, Valagussa P, Moliterni A et al (1995) Adjuvant cyclophosphamide, methotrexate, and fluorouracil in node-positive breast cancer. N Engl J Med 332:901-906

2. Epelbaum R, Faraggi D, Ben-Arie Y et al (1990) Survival of diffuse large cell lymphoma. A multivariate analysis including dose intensity variables. Cancer 66:1124-1129 
3. Dewys WD, Begg C, Lavin PT et al (1980) Prognostic effect of weight loss prior to chemotherapy in cancer patients. Am J Med 69: 491-497

4. Alexandre J, Gross-Goupil M, Falissard B et al (2003) Evaluation of the nutritional and inflammatory status in cancer patients for the risk assessment of severe haematological toxicity following chemotherapy. Ann Oncol 14:36-41

5. Roila F, Herrstedt J, Aapro M et al (2010) Guideline update for MASCC and ESMO in the prevention of chemotherapy- and radiotherapy-induced nausea and vomiting: results of the Perugia consensus conference. Ann Oncol 21:S232-S243

6. Basch E, Prestrud AA, Hesketh PJ et al (2011) Antiemetics: American society of clinical oncology clinical practice guideline update. J Clin Oncol 29:4189-4198

7. National Comprehensive Cancer Network (NCCN) (2011) Clinical practice guidelines in oncology-antiemesis-versioni. http://www. nccn.org/professionals/physician_gls/PDF/antiemesis.pdf (Accessed April 12,2012)

8. Roila F, Hesketh PJ, Herrstedt J et al (2006) Prevention of chemotherapy- and radiotherapy-induced emesis: results of the 2004 Perugia International Antiemetic Consensus Conference. Ann Oncol 17:20-28

9. Herrstedt J, Roila F, ESMO Guidelines Working Group (2008) Chemotherapy-induced nausea and vomiting: ESMO clinical recommendations for prophylaxis. Ann Oncol 19:110-112

10. Wilder-Smith OH, Borgeat A, Chappuis P et al (1993) Urinary serotonin metabolite excretion during cisplatin chemotherapy. Cancer 72:2239-2241

11. Ohmatsu H, Eguchi K, Shinkai T et al (1994) A randomized crossover study of high-dose metoclopramide plus dexamethasone versus granisetron plus dexamethasone in patients receiving chemotherapy with high-dose cisplatin. Jpn J Cancer Res 85:1151-1158

12. Tattersall FD, Rycroft W, Francis B et al (1996) Tachykinin NK1 receptor antagonists act centrally to inhibit emesis induced by the chemotherapeutic agent cisplatin in ferrets. Neuropharmacology 35:1121-1129

13. Huskey SE, Dean BJ, Bakhtiar R et al (2003) Brain penetration of aprepitant, a substance P receptor antagonist, in ferrets. Drug Metab Dispos 31:785-791

14. Hesketh PJ, Van Belle S, Aapro M et al (2003) Differential involvement of neurotransmitters through the time course of cisplatininduced emesis as revealed by therapy with specific receptor antagonists. Eur J Cancer 39:1074-1080

15. Watson JW, Gonsalves SF, Fossa AA et al (1995) The anti-emetic effects of CP-99,994 in the ferret and the dog: role of the NK1 receptor. Br J Pharmacol 115:84-94

16. Andrews PL, Bhandari P (1993) Resinferatoxin, an ultrapotent capsaicin analogue, has anti-emetic properties in the ferret. Neuropharmacology 32:799-806

17. Ballard TM, Sänger S, Higgins GA et al (2001) Inhibition of shockinduced foot tapping behaviour in the gerbil by a tachykinin $\mathrm{NK}_{1}$ receptor antagonist. Eur J Pharmacol 412:255-264

18. Rupniak NM (2002) Elucidating the antidepressant actions of substance $\mathrm{P}\left(\mathrm{NK}_{1}\right.$ receptor) antagonists. Curr Opin Investig Drugs 3: 257-261

19. Hesketh PJ, Grunberg SM, Gralla RJ et al (2003) The oral neurokinin-1 antagonist aprepitant for the prevention of chemotherapy-induced nausea and vomiting: a multinational, randomized, double-blind, placebo-controlled trial in patients receiving high-dose cisplatin -the aprepitant protocol 052 study group. J Clin Oncol 21:4112-4119

20. Grunberg S, Chua D, Maru A et al (2011) Single-dose fosaprepitant for the prevention of chemotherapy-induced nausea and vomiting associated with cisplatin therapy: randomized, double-blind study protocol-EASE. J Clin Oncol 29:1495-1501

21. Saito H, Yoshizawa H, Yoshimori K et al (2013) Efficacy and safety of single-dose fosaprepitant in the prevention of chemotherapyinduced nausea and vomiting in patients receiving high-dose cisplatin: a multicentre, randomised, double-blind, placebo-controlled phase 3 trial. Ann Oncol 24:1067-1073

22. Takahashi T, Hoshi E, Takagi M et al (2010) Multicenter, phase II, placebo-controlled, double-blind, randomized study of aprepitant in Japanese patients receiving high-dose cisplatin. Cancer Sci 101: 2455-2461

23. Poli-Bigelli S, Rodrigues-Pereira J, Carides AD et al (2003) Addition of the neurokinin 1 receptor antagonist aprepitant to standard antiemetic therapy improves control of chemotherapy-induced nausea and vomiting -results from randomized, double-blind, placebo-controlled trial in Latin America. Cancer 97:3090-3098

24. Warr DG, Hesketh PJ, Gralla RJ et al (2005) Efficacy and tolerability of aprepitant for the prevention of chemotherapy-induced nausea and vomiting in patients with breast cancer after moderately emetogenic chemotherapy. J Clin Oncol 23:2822-2830

25. Longo F, Mansueto G, Lapadula V et al (2012) Combination of aprepitant, palonosetron and dexamethasone as antiemetic prophylaxis in lung cancer patients receiving multiple cycles of cisplatinbased chemotherapy. Int J Clin Pract 66:753-757

26. Koeller JM, Aapro MS, Gralla RJ et al (2002) Antiemetic guidelines: creating a more practical treatment approach. Support Care Cancer 10:519-522

27. Koizumi W, Narahara H, Hara T et al (2008) S-1 plus cisplatin versus S-1 alone for first-line treatment of advanced gastric cancer (SPIRITS trial): a phase III trial. Lancet Oncol 9:215-221

28. Sekine I, Segawa Y, Kubota K et al (2013) Risk factors of chemotherapy-induced nausea and vomiting: index for personalized antiemetic prophylaxis. Cancer Sci 104:711-717

29. Barrajon E, de las Peñas R (2000) Randomized double blind crossover study comparing ondansetron, granisetron and tropisetron. A cost-benefit analysis. Support Care Cancer 8:323-333

30. del Giglio A, Soares HP, Caparroz C et al (2000) Granisetron is equivalent to ondansetron for prophylaxis of chemotherapyinduced nausea and vomiting: results of a meta-analysis of randomized controlled trials. Cancer 89:2301-2308

31. Tsukuda M, Mochimatsu I, Furukawa M et al (1995) A randomized crossover comparison of azasetron and granisetron in the prophylaxis of emesis induced by chemotherapy including cisplatin. Gan To Kagaku Ryoho 22:1959-1967

32. Hashimoto H, Yamanaka T, Shimada Y et al. (2013) Palonosetron (PALO) versus granisetron (GRA) in the triplet regimen with dexamethasone (DEX) and aprepitant (APR) for preventing chemotherapy-induced nausea and vomiting (CINV) in patients (pts) receiving highly emetogenic chemotherapy (HEC) with cisplatin (CDDP): a randomized, double-blind, phase III trial. J Clin Oncol 31 (supple; abstr 9621)

33. Aoki S, Iihara H, Nishigaki M et al (2013) Difference in the emetic control among highly emetogenic chemotherapy regimens: implementation for appropriate use of aprepitant. Mol Clin Oncol 1:41-46 